\title{
Understanding and Analysis of "To Bear the Shame" and Its Enlightenment to Contemporary College Students
}

\author{
Shen Yanbin ${ }^{1, \mathrm{a}}$, Liu Boyu ${ }^{2, \mathrm{~b}}$, Hu Gangcheng ${ }^{3, \mathrm{c}}$, Liu Xiwen ${ }^{4, \mathrm{~d}}$ \\ ${ }^{l}$ School of management, South China Business College of Guangdong University of Foreign Studies, Zhong Luotan \\ Town, Baiyun District, Guangzhou City, Guangdong Province, China \\ ${ }^{2}$ School of Agriculture, Baiyun District, Guiyang City, Guizhou Province, China \\ ${ }^{3}$ International Economics and Finance, North campus of Guangdong Baiyun University, Zhong Luotan Town, Baiyun \\ District, Guangzhou City, Guangdong Province, China \\ ${ }^{4}$ Translation, South China Business College of Guangdong University of Foreign Studies, Zhong Luotan Town, Baiyun \\ District, Guangzhou City, Guangdong Province, China \\ 1050396079@qq.com \\ b2281110449@qq.com \\ c2311349711@qq.com \\ dshigan333931@163.com
}

\begin{abstract}
Mao Zedong's art of war contains the philosophy of mind, which is in line with his favorite poem, "The Inscription of Wujiang Pavilion". Among them, the "endure", a part of the mind method of the poem analyzed in this paper, in view of the understanding of the meaning of "covering shame and enduring shame" and Mao Zedong's application of it, puts forward the inspiration that contemporary college students should get from it, and provides reference and reference for college students to use this mind method.
\end{abstract}

Keywords: Enduring the shame, contemporary college students, Mao Zedong's method of thinking, enlightenment

\section{“包差忍耻”的理解分析和其对当代大学生的启示}

\author{
沈彦兵 $^{1, a}$, 刘博宇 ${ }^{2, b}$, 胡刚丞 ${ }^{3, c}$, 刘熙文 $^{4, \mathrm{~d}}$
}

1 广东外语外贸大学南国商学院管理学院, 钟落潭镇, 白云区, 广州市, 广东省, 中国

兴农中学, 白云区，贵阳市，贵州省，中国

3 广东白云学院北校区国际经济与贸易系, 钟落潭镇, 白云区, 广州市, 广东省，中国

${ }^{4}$ 广东外语外贸大学南国商学院翻译系, 钟落潭镇, 白云区, 广州市, 广东省, 中国

1050396079@qq.com

b2281110449@qq.com

c2311349711@qq.com

dshigan333931@163.com

摘要: 毛泽东兵法之中蕴含了心法的哲理, 符合他生前最喜欢的诗《题乌江亭》中。其中, 本文所分析的诗 其心法的一部分 “忍”, 针对对 “包差忍辱” 含义的理解和毛泽东对它的运用, 来提出当代大学生应该从中得 到的启发, 为大学生运用此心法提供借鉴与参考。

关键词：包着忍辱；当代大学生；毛泽东心法；启示 


\section{1. 引言}

毛泽东兵法是毛泽东早期各项军事活动及其军 事理论的来源, 是毛泽东思想中最活跃、最生动的部 分, 是毛泽东调动军队在中国革命战争中不断发展壮 大, 由弱而强的根本原因。毛泽东兵法在中国革命战 争中有着举足轻重的终于地位, 而毛泽东心法则贯穿 了整套兵法体系的始终, 为我国游击战等一系列持久 战奠定了心理基础, 引领中国人民解放军越挫越勇, 最终得以获得以寡敌众的胜利。其中, 毛泽东兵法中 的心法是毛泽东得以多次以弱胜强的关键因素, 本文 对该心法中的 “包差忍耻” 部分进行研究, 以此得出 当代大学生应当从中获取的精髓, 并可以在日常生活 中运用的启示进行分析, 以就教于方家。

\section{2. 对毛泽东心法的理解}

\section{1. 对毛泽东最喜欢的诗 《题乌江亭》的理解}

\section{1. 1. 《题乌江亭》的释义和中心思想}

杜牧所写的《题乌江亭》是毛泽东生前最喜欢的 诗, 也是毛泽东经常写给别人的事, 这首看似简单的 诗却饱含了毛泽东心法中最重要的思想, 而这一思想 成为了毛泽东用兵制胜的法宝, 也是中国人民解放军 得以在中国解放战争中最终获胜的关键。这首诗的释 义为: 战争胜败的事是很难预料的, 唯有不怕挫折能 忍受耻辱的, 才是真正的男子汉。江东这个地方人才 很多, 若能吸取教训, 重整旗鼓, 卷土重来也是说不 定的。这首诗是一首咏史诗, 是诗人针对项羽兵败身 亡的教训得出的心得而发出的感慨。

\section{1. 2. 毛泽东提取《题乌江亭》思想的中心}

在杜牧的《题乌江亭》一诗中, 有一句诗道: “胜 败兵家事不期, 包差忍耻是男儿”。其中的 “包差忍 耻” 是毛泽东心法所提炼的中心思想。其意谓大丈夫 应能屈能伸, 拥有忍受屈耻的胸襟和气度, 在必要时 刻敢于承受耻辱的苦痛, 不断默默壮大自身, 才能养 精蓄锐在关键时刻取得先机。这个军事思想在毛泽东
军事战略领导中发挥了重要的作用, 让中国人民解放 军拥有强大的意志, 高举解放思想的旗帜, 与敌人进 行长久的搏击战, 为中国共产党的胜利赢得了关键因 素。

\section{2. 章士刢的《柳文指要》与毛泽东兵法的联 系}

\subsection{1. 毛泽东对《柳文指要》的重视}

章士钊从 1960 年开始，用了五年的时间撰写了 《柳文指要》, 这是第一本系统地全面地研究柳宗元 文集的专著。毛泽东对其初稿的完成十分的重视，提 出将书稿先赠他一读, 并多次亲自修改文章, 还将其 推荐给康生阅读, 自己不断反复推敲书中柳宗元思想 的精髓, 并深入地分析和评价此书。在文革时期, 毛 泽东还破格地特别关照此书的出版，评价它为 “义正 词严，敬服之至”。章士钊也对毛泽东对柳宗元思想 的深入研究在总序中做出了评价, 认为毛泽东的成功 与他不断汲取古人的思想精髓并以读易补过，倍百恒 品的学习精神密不可分。

\section{2. 2. 《柳文指要》中的思想对毛泽东心法的 指导作用}

毛泽东生前对柳宗元思想十分重视，他称赞柳宗 元突出的唯物论思想和政治改革主张, 是历史诗文作 家中罕见的唯物思想和进步历史理论建树的人。在此 之中, 柳宗元的民本政治思想对毛泽东心法的影响最 为深远。柳宗元认为官吏是人民的奴仆，并非人民是 官员的奴仆，这影响了毛泽东后期提出 “一切为了群 众，一切依靠群众，从民众中来到民众中去” 的群众 路线思想和 “全心全意为人民服务” 的中国共产党宗 旨。工人和农民虽然暂时是被压迫的阶级，但当他们 包差忍辱、养精蓄锐团结起来时爆发的力量是巨大的, 这股力量是不能被忽视的, 停止压迫, 守护和平, 这 是广大群众的意愿, 是广大人民群众利益的真实反映, 也是毛泽东提出的星星之火可以燎原的来源。 


\section{3. “包差忍耻” 在不同时期的应用启示分析}

\section{1. 毛泽东在抗战时期对 “包甶忍耻” 心法的 运用}

\section{1. 1. 红军长征时期中国共产党的“包差忍耻”}

红军长征是人类历史上的伟大奇迹, 当时国共两 党对峙, 共产党势力较弱, 受到国民党的围剿。1934 年 10 月, 在共产党第五次反围剿失败后, 共产党红 军为了摆脱国民党军队的包围追击, 他们包差忍耻被 迫实行战略性转移, 退出了中央根据地, 开始进行长 达 1.8 万公里的长征。然而, 共产党并没有就此因为 势力单薄而甘愿受耻, 在长征路途中不断收拢民心, 奋力与国民党军队进行抗击, 最终在甘肃会宁地区成 功会师, 并逐渐发展壮大, 始终不气馁, 准备与国民 党进行持久战。

\section{1. 2. 井风山革命根据地的 “卷土重来”}

“包差忍耻” 的忍只是暂时的一种战术, 而紧随 其后伴随的便是 “卷土重来” 的狠。中国共产党能屈 能伸, 在被迫转移到井冈山革命根据地之后在根据地 默默发展壮大, 拢络民心, 始终坚持民本路线, 最终 决定采用农村包围城市的道路。毛泽东率领秋收起义 的部队与朱德等人领导的湘南起义部队与贺龙领导 的南昌起义部队, 最终得以养精蓄锐, 躲过国民党的 围剿, 在井冈山胜利会师, 靠的便是 “包差忍辱” 的 心理战。农民和工人阶级虽然在当时是被剥削压迫的 阶级, 但是他们与共产党一道承受着包差忍耻, 就是 为了等待突破的一天。最终, 中国共产党成功会师后 得以卷土重来, 不仅是依靠自身坚忍不拔的毅力, 更 依靠的是老百姓“量小非君子, 无毒不丈夫”的兵法, 虽然革命的过程是艰险的, 但共产党人坚信革命的未 来是光明的, 赢得美好生活的胜利终将到来。

\section{2. 当代大学生对 “包差忍耻” 的应用启示}

\section{2. 1. 大学生活和学习上的 “包羞忍耻” 应用}

大学生活对每个新生来说都有一段或长或短的 适应期, 每个人对新环境的适应的速度都是不一样的。 这其中必定有些人是慢热的, 而他们难免会被身边一 些更快适应的学生排斥, 他们会觉得自己也有做出最 大程度的努力但总是看不到成果而因此感到困扰。遇 到这类情况就可以运用 “包差忍耻” 的心法, 调整好 自己的心态, 认识到自身的努力和缺陷, 默默地弥补
弱势, 好汉不吃眼前亏, 当一切都准备妥当后, 只需 要静静等待东风到来, 等到适当的时机才能做到一鸣 惊人。只有能承担外界的压力, 有强大的心理素质和 精神支柱作为寄托，才能真正运用 “包差忍耻” 的精 髓, 在大学生活中活出精彩的自我。

\subsection{2. 应届大学生新入职场中对 “包羞忍耻” 的应用}

在这个快速发展的时代，应届大学生作为职场的 新晋小白，难免会被职场上的老员工难或者排斥， 这是每个大学生踏入职场都会面临的难题。在这个适 应过程中，运用好 “包差忍耻” 心法会让自己的心态 更加平衡, 更快地调节自己去适应现状。在这个时代 快速发展，人才市场竞争强烈且职场竞争激烈的年代， 应届大学生虽然大部分在硬件技能方面有所提高, 但 心理素质仍然有待提高, 应对职场上各种各样的挫折 和困难仍然没有具备完备的心理应对能力, 这也导致 了越来越多抑郁症等心理疾病的产生。因此我们应当 提高自己的心理承受能力, 清楚地认识到自己的职场 经验不足之处，虚心请教前辈，不断默默提升自己的 工作能力的同时也要有应对困难时临危不惧, 越挫越 勇的心态, 深知 “包差忍辱” 的道理。同时, 也要抓 住机遇，做到当机遇来临的时候自己已经做好足够的 准备来展现自己的实力, 让领导们看到自己的闪光点, 从而快速获得认同感。

\section{4. 结论}

本文研究了毛泽东“包差忍耻”心法的来源释义、 中心思想和在同时期的实践应用，得出了关于当代大 学生可以借鉴该心法的实例拓展。对该心法的应用进 行了更多的使用领域分析, 并从中与当代大学生发展 状况进行了结合，从而得出启发。“包差忍辱”心法 是毛泽东在战役时期获得制胜的关键, 也是红军长征 持久战的制胜心法，它无论在战争时期亦或是和平年 代对于我们当代大学生来说都有着深远的指导意义。 践行 “包差忍耻” 心法的过程也是磨练人的心智和毅 力的历程, 唯有掌握 “包差忍耻” 才能成为大丈夫, 抓紧关键时机将自己忍受的 “耻辱” 转变为积极向上 的力量, 在默默无闻中磨练自己的 “利刃”, 才能最 终一举得胜, 扭转局势, 从而获得功与名。

\section{项目基金:}

[1］《基于 EAP 理念下社区帮扶与朋辈咨 
询双模式下非常规恋爱观的调查与对策》,

一般项目, 哲学社会科学类社会调查报告 和学术论文, pdjh2021b0686

[2]《建立校园招聘市场实操践行的策略 探讨一一基于创造大学生实体企业 “南国人才 市场” 的思考》,

一般项目，哲学社会科学类社会调查报告 和学术论文, Pdjh2019b0654

\section{REFERENCES}

[1] Guo Huaqing,(2019)On Zhang Shizhao's Historical Normal View in His Late Years from Liu Wen's Instructions[J].40(09):12-15.

[2] Guo Huaqing,(2019)People-oriented: The Core Idea of Liu Wen's Instructions[J].Journal of Qinghai Normal University (Philosophy and Social Sciences Edition),41(04):22-29.

[3] Meng Zhaogeng,(2016)Mao Zedong strongly supported Zhang Shizhao "LiuWen Instructions" published inside information[J].The history issue,(03):9-14.

[4] Zhao Kun,(2014)Politics and Academics in "Extreme Writing" -- RereadingZhang Shizhao's Instructions on Liu Wen[J].Journal of Modern Chinese Studies,(06):67-73.

[5] Han Shujing,(2010)A Comparison between Title Wujiang Pavilion and Wujiang Pavilion[J].Literary Education (2),(05):24-25.

[6] Wang Lihua,(2019)On Mao Zedong's winning method[J].Cultural soft power,4(04):43-52.

[7] Nan Sheng,(2005)To bear the shame it's the men[J].The writing,(18):18.

[8] Yellow Holy Week. The Thought of Tolerance in Chinese Culture $[\mathrm{J}]$. Xianning College Journal, 2006 (04): 41-44.
[9] Ren Xiaowei. The Effect of Sun Tzu's Law of War on Mao Zedong's Military Strategic Thought during the Revolutionary Period [J]. Journal of China Yan'an Cadre Academy, 2018,11 (02): 100-104.

[10] Wang Xiaojun. On Mao Zedong's learning, inheritance and practical application of Sun Tzu's Law of War [J]. Sun Tzu Research, 2017 (05): 44-52.

[11] Guo Huaqing. From "Liu Wen refers to" to see Zhang Shizhao's "Four People" cooperation thought [J]. Journal of Guangzhou University (Social Sciences Edition), 2019,18 (04): 107-114. 